\title{
Simulation of Microstructure during Laser Rapid Forming Solidification Based on Cellular Automaton
}

\author{
Zhi-jian Wang, ${ }^{1}$ Shuai Luo, ${ }^{1}$ Hong-wu Song, ${ }^{2}$ Wei-dong Deng, ${ }^{1}$ and Wen-yi Li ${ }^{1}$ \\ ${ }^{1}$ School of Mechatronics Engineering, Shenyang Aerospace University, Shenyang, Liaoning 110136, China \\ ${ }^{2}$ Institute of Metal Research, Chinese Academy of Sciences, Shenyang, Liaoning 110016, China \\ Correspondence should be addressed to Zhi-jian Wang; wangzhijian1974@sina.com
}

Received 9 June 2014; Accepted 15 July 2014; Published 5 August 2014

Academic Editor: Jun Liu

Copyright (C) 2014 Zhi-jian Wang et al. This is an open access article distributed under the Creative Commons Attribution License, which permits unrestricted use, distribution, and reproduction in any medium, provided the original work is properly cited.

\begin{abstract}
The grain microstructure of molten pool during the solidification of TC4 titanium alloy in the single point laser cladding was investigated based on the CAFE model which is the cellular automaton (CA) coupled with the finite element (FE) method. The correct temperature field is the prerequisite for simulating the grain microstructure during the solidification of the molten pool. The model solves the energy equation by the FE method to simulate the temperature distribution in the molten pool of the single point laser cladding. Based on the temperature field, the solidification microstructure of the molten pool is also simulated with the CAFE method. The results show that the maximum temperature in the molten pool increases with the laser power and the scanning rate. The laser power has a larger influence on the temperature distribution of the molten pool than the scanning rate. During the solidification of the molten pool, the heat at the bottom of the molten pool transfers faster than that at the top of the molten pool. The grains rapidly grow into the molten pool, and then the columnar crystals are formed. This study has a very important significance for improving the quality of the structure parts manufactured through the laser cladding forming.
\end{abstract}

\section{Introduction}

Currently, the laser cladding technology has become the new breakthrough of the complex structure parts for aviation manufacturing process. In the laser cladding technology, the high input heat can make the surface of the substrate and the laser cladding material melt and then the molten pool is formed. It avoids the disadvantages of high machining allowances in the traditional process, long computer numerically controlled (CNC) machining time, low material utilization, long production cycles and high manufacturing cost [1-3]. Figure 1 is the principle of laser cladding forming. In the process of laser cladding forming, the substrate is heated by laser beam which results in melting the thin layer of metal on the substrate surface. And then the molten pool is formed with the powders offered by powder feeder [4].

The solidification of the molten pool is a very complex and unbalanced rapid solidification process. It is difficult to observe the growth of grains during the solidification of molten pool experimentally because of the high temperature and the rapid solidification rate affected by the size of the molten pool and the material features. With the development of the computer science, the numerical simulation technology is a good method to analyze the growth of grains in the solidification of molten pool. It contributes to revealing the evolution of microstructures and improving the quality of the workpiece in the laser cladding forming.

The researches on the microstructure simulation have achieved many significant accomplishments since the end of the last century $[5,6]$. Several kinds of calculation methods about nucleation and growth of the grains during the solidification of materials were presented from these researches including deterministic modeling, stochastic modeling, and phase-field modeling [7]. Because of the determinacy of the deterministic modeling, it cannot simulate the random growth of grains such as random nucleation and random crystal orientation. Phase-field modeling which avoids the difficulty of tracking the complex solid-liquid interface has disadvantages that slow computing speed, inefficiency, and small simulated area $[8,9]$.

Cellular automaton (CA) which is a kinetic and stochastic model scattered in time, space, and state has been widely 


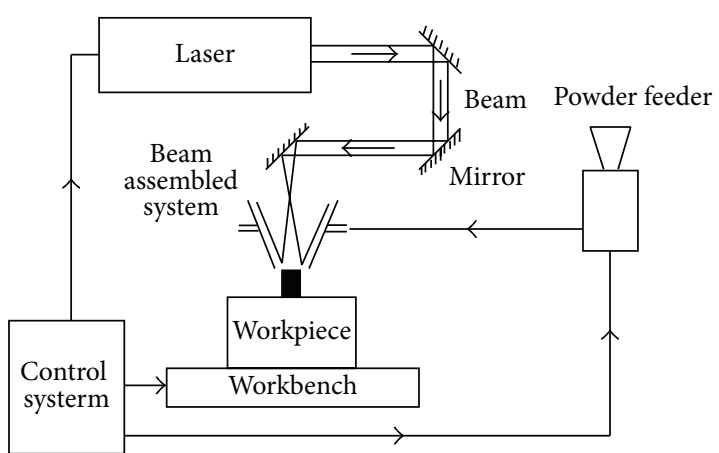

FIgURE 1: Principle of the laser cladding forming.

used in solidification and recrystallization of the material science in recent decades [7]. Based on the solidification thermodynamic, grain nucleation, and growth kinetics, it can simulate the growth of the grains in the solidification of the molten pool and determine the locations of the nucleation and crystallization orientation. Cellular automaton has a certain physical foundation. The simulated microstructure is not dependent on the meshes of the model and the computation speed is faster than other methods and the computation area is larger.

Shang et al. [10] researched the various defects which may be caused in forming parts on account of technical parameters, equipment performance, material characteristics, and other factors in the process of metal powder laser rapid forming. The results show that less or over accumulation resulting from powder feed delay is the main reason for affecting the dimensional accuracy of cladding and the main reason which affects the appearance of surface sticky powder is specific energy. Lin et al. [11] studied the solidification behavior and morphological evolution of 316L stainless steel during laser rapid forming. It is found that the sample completely consisted of columnar $\gamma$ austenitic dendrites which grow epitaxially from the base. Zhan et al. [12] established a cellular automaton-finite difference model and simulated the dendritic grains in the weld pool of $\mathrm{Ni}-\mathrm{Cr}$ binary alloy. The results reproduce the growth of secondary and tertiary dendrite arms, the competitive growth and the grain boundary segregation, and so forth. Seo et al. [13] predicted the solidification of the grain structures in a Ni-base superalloy based on a three-dimensional cellular automaton model coupled with finite-element heat flow calculation. An empirical relationship between the nucleation density at the surface and the initial cooling time of the melt was proposed and applied to the input parameter in the model for describing the Gaussian distribution of nucleation sites at the mold surface. Yin and Felicelli [14] simulated the dendritic growth occurring in the molten pool during the laser-engineered net shaping process. Based on the simulation results and experimental data, empirical expressions describing the relationship between the cooling rate and the dendrite arm spacing were proposed.

In this paper, compared with the experimental microstructures, a model combining the cellular automaton and the finite element method was developed to simulate the growth of the grain occurring in the molten pool during the single point laser cladding based on the temperature distribution.

\section{Model Theory}

2.1. Heat Transfer Model. The temperature distribution has a significant impact on the grain microstructure in the molten pool. The heat transfer model [15] used in this paper is shows as follows:

$$
\rho c \frac{\partial T}{\partial t}=\frac{\partial}{\partial x}\left(k \frac{\partial T}{\partial x}\right)+\frac{\partial}{\partial y}\left(k \frac{\partial T}{\partial y}\right)+\frac{\partial}{\partial z}\left(k \frac{\partial T}{\partial z}\right),
$$

where $\rho$ is the density, $c$ is the specific heat, $T$ is the temperature, $t$ is the time, and $x, y$, and $z$ are the coordinates of the calculated area, respectively.

The enthalpy is defined in this paper to solve the release of the latent heat during the solidification of the molten pool:

$$
H(T)=\int_{0}^{T} c d T+L\left(1-f_{s}\right),
$$

where $H(T)$ is the enthalpy, $L$ is the latent heat, and $f_{s}$ is the solid fraction.

2.2. Nucleation. In terms of the nucleation of the solidification in the molten pool, the paper considers only the heterogeneous nucleation. For simulating the growth of the grain, a continuous nucleation model which was proposed by Rappaz and Gandin $[16,17]$ was used. The model assumes that the nucleation happens on a range of different nucleation locations. The continuous and nondiscrete distribution, $d n / d(\Delta T)$, is used to describe the grain density increased with the increase of the undercooling. The total density of nucleation with a given $\Delta T$ is determined as follows:

$$
n(\Delta T)=\int_{0}^{\Delta T} \frac{d n}{d(\Delta T)} d(\Delta T) .
$$

Gaussian distribution of nucleation sites is assumed to account for the heterogeneous nucleation in the molten pool:

$$
\frac{d n}{d(\Delta T)}=\frac{n_{\max }}{\sqrt{2 \pi} \Delta T_{\sigma}} \exp \left[-\frac{1}{2}\left(\frac{\Delta T-\Delta T_{\max }}{\Delta T_{\sigma}}\right)^{2}\right],
$$

where $n_{\max }$ is the maximum nucleation density, $\Delta T_{\sigma}$ is the standard deviation of the distribution, and $\Delta T_{\max }$ is the mean nucleation undercooling. The locations of nucleation are chosen randomly among all the cellular automaton sites. Figure 2 shows the Gaussian distribution for nucleation sites.

The parameters of the Gaussian distribution for nucleation sites have a deep effect on the growth of the grains. The area of the columnar crystal increases with the mean nucleation undercooling. The increase of the standard deviation undercooling results in the decrease of the grains which have the minimum area but the uniformity of these grains deceases firstly and then increases. The maximum nucleation density contributes to the decrease of the grain size. 


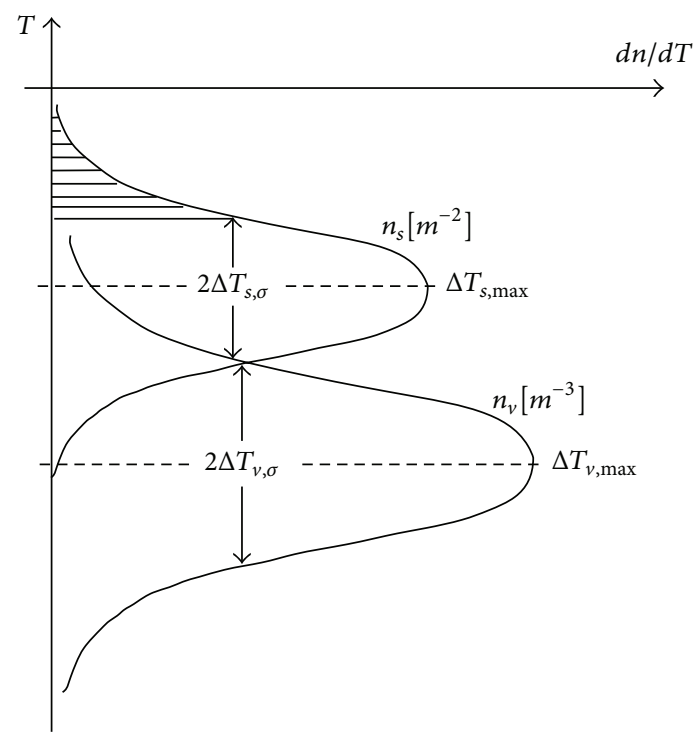

FIGURE 2: Gaussian distribution for nucleation sites.

2.3. Grain Growth. In the present paper, the Kurz-GiovanolaTrivedi (KGT) model $[16,18]$ is used to describe the growth kinetics of the grains. The model reasonably considers the influence of the undercooling and the curvature of the grain tip on the growth velocity of grain tip. The model is described as follows:

$$
\begin{gathered}
\Delta T=\Delta T_{c}+\Delta T_{t}+\Delta T_{r}+\Delta T_{k}, \\
\Omega=\frac{c^{*}-c_{0}}{c^{*}(1-k)}, \\
R=2 \pi v \Gamma \sqrt{\left(m G_{c} \xi_{c}-G\right)},
\end{gathered}
$$

where $\Delta T_{c}, \Delta T_{t}, \Delta T_{r}$, and $\Delta T_{k}$ are the undercoolings which are associated to solute diffusion, thermal diffusion, growth kinetics, and curvature of the solid-liquid interface, respectively. For most metallic alloys, the last three undercoolings can be ignored. $\Omega$ is the solute supersaturation, $R$ is the radius of the grain tip, $c_{0}$ is the initial concentration of the alloy elements, $c^{*}$ is the liquidus concentration at the tip of the solid-liquid interface, $k$ is the partition coefficient, $m$ is the slope of the liquidus, $\Gamma$ is the Gibbs-Thomson coefficient, $G_{c}$ is the liquidus solute concentration gradient at the tip of the grain, and $G$ is the temperature gradient.

The relationship between the undercooling, $\Delta T$, and the solute supersaturation, $\Omega$, is shown as follows:

$$
\Delta T=m c_{0}\left[1-\frac{1}{\Omega(1-k)}\right] .
$$

In order to accelerate the calculation, the paper fitted the KGT model in the process of the realistic simulation. And then the growth velocity of the grain tip can be obtained:

$$
v(\Delta T)=a_{2} \Delta T^{2}+a_{3} \Delta T^{3},
$$

where $a_{2}$ and $a_{3}$ are the coefficients of the polynomial and $\Delta T$ is the total undercooling of the grain. $a_{2}$ and $a_{3}$ can be obtained from Table 1 .

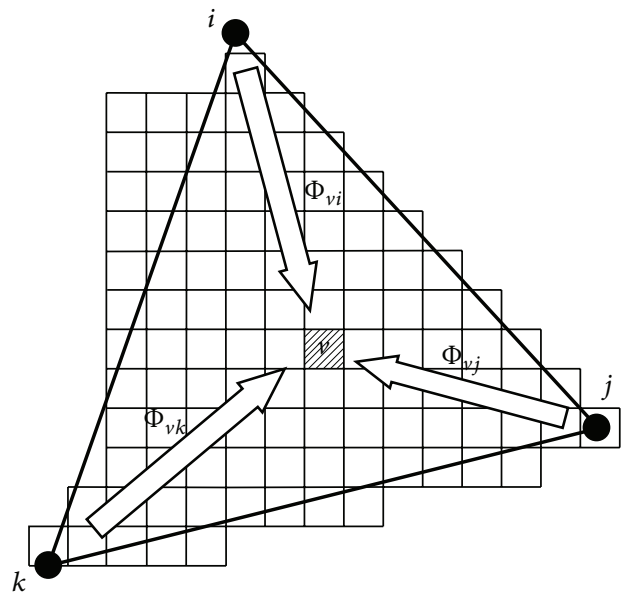

FIGURE 3: CA cell, $v$, which has three nonzero interpolation coefficients $\Phi_{v i}, \Phi_{v j}$, and $\Phi_{v k}$ and finite element which has three nodes $i, j$, and $k$.

\section{Coupling Principle of CAFE}

The finite element (FE) enmeshments can calculate the heat flow and the temperature gradients in the laser rapid forming. Based on the result of the macroscopic finite element, the cellular automaton (CA) units which are square cells with smaller sizes perform the calculations to simulate the growth of the grains in the laser rapid forming. In order to combine the CA and FE calculations, three nonzero interpolation coefficients $\Phi_{v i}, \Phi_{v j}$, and $\Phi_{v k}$ are defined between nodes of the CA cells and FE meshes. A CA cell, $v$, has three nonzero interpolation coefficients $\Phi_{v i}, \Phi_{v j}$, and $\Phi_{v k}$, respectively, in the center of the finite element which has three nodes $i$, $j$, and $k$ in Figure 3. The nonzero interpolation coefficients can determine the temperature of the CA cell based on the surrounding three finite element nodes. The aim of this is to couple the CA and FE calculations and simulate the growth of the grain as a function of the thermal field [19].

Obviously, the temperature of the finite element units has a deep effect on the temperature of the CA units. The relationship on temperature between the finite element and the cellular automaton is shown as follows [12]:

$$
T_{P}=\frac{\sum_{i=1}^{N} l_{i}^{-1} T_{i}}{\sum_{i=1}^{N} l_{i}^{-1}},
$$

where $T_{p}$ is the temperature of the cellular automaton unit, $T_{i}$ is the temperature of the finite element unit correlated with cellular unit, $l_{i}$ is a distance from the cellular automaton to the finite element node, and $N$ is the number of the surrounding macroscope finite element nodes.

\section{Simulation}

4.1. Geometry Model. Figure 4 shows the geometry model and mesh of the single point laser cladding. In order to improve the calculation precision, the size of the surface mesh is $0.1 \mathrm{~mm}$ in the area of molten pool and the size of the surface 
TABLE 1: Calculation parameters of grain tip growth kinetics coefficients.

\begin{tabular}{lccccc}
\hline Elements & $\begin{array}{c}\text { Initial concentration } \\
c_{0}(\%)\end{array}$ & $\begin{array}{c}\text { Partition } \\
\text { coefficient } k\end{array}$ & $\begin{array}{c}\text { Liquidus slope } \\
m_{l}\left({ }^{\circ} \mathrm{C} / \mathrm{wt} \%\right)\end{array}$ & $\begin{array}{c}\text { Diffusion coefficient } \\
\text { in liquid } D_{l}\left(\mathrm{~m}^{2} / \mathrm{s}\right)\end{array}$ & $\begin{array}{c}\text { Gibbs-Thomson } \\
\text { coefficient }(\mathrm{K} \cdot \mathrm{m})\end{array}$ \\
\hline $\mathrm{Al}$ & 6.1 & 0.9 & -1190 & & $10^{-9}$ \\
$\mathrm{~V}$ & 4.2 & 0.8 & -1500 & & $2 \times 10^{-7}$ \\
$\mathrm{Fe}$ & 0.15 & 0.07 & -2000 & & \\
\hline
\end{tabular}
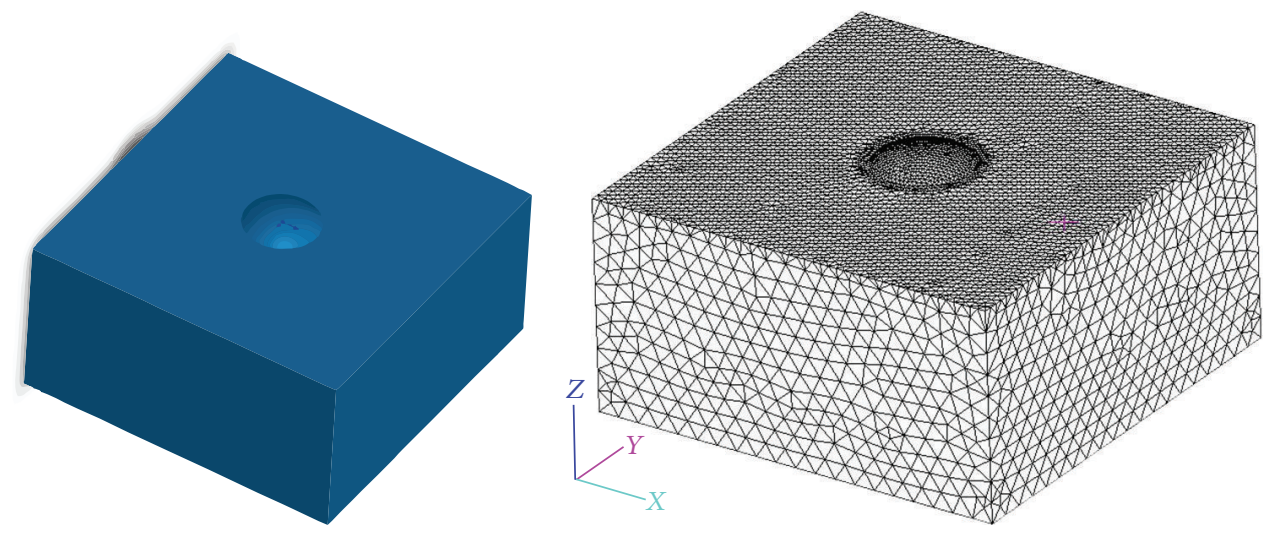

FIGURE 4: Geometry model and mesh of the single point laser cladding.

mesh on the base is $0.5 \mathrm{~mm}$. And then the volume mesh can be generated automatically. The total number of nodes is 32653 and the number of elements is 172478 .

4.2. Thermophysical Parameters. In order to ensure the accuracy of the results in the simulation of the grain growth, the parameter database is created about the material of the solved model. The material used in this study is TC4 titanium alloy including $6.1 \mathrm{wt} \% \mathrm{Al}, 4.2 \mathrm{wt} \% \mathrm{~V}$, and few impurity elements. The liquidus temperature is $1718^{\circ} \mathrm{C}$ and the solidus temperature is $1649^{\circ} \mathrm{C}$. The material physical properties including conductivity, density, enthalpy, and fraction-solid are shown in Figure 5.

4.3. Boundary Conditions. The energy transfers from the molten pool to the surroundings in single point laser cladding through the base. The temperature field is three-dimensional erratic heat-transfer model in the solidification of the molten pool. The temperature distribution at a time is selected as the initial condition [16]:

$$
\left.T(x, y, z, t)\right|_{B}=T_{0}=20,
$$

where $B$ is the boundary of the solving area and $T_{0}$ is the initial temperature (room temperature).

The heat convection between the solving model and the surrounding fluid medium is another boundary condition in the heat transfer process [20]. The heat transfer coefficient is $10 \mathrm{~W} / \mathrm{m}^{2} \cdot{ }^{\circ} \mathrm{C}$ and the surrounding temperature is $20^{\circ} \mathrm{C}$ :

$$
-\left.\lambda \frac{\partial T}{\partial n}\right|_{B}=\left.h\left(T-T_{f}\right)\right|_{B}=10\left(T_{B}-20\right),
$$

where $h$ is the heat transfer coefficient, $T_{f}$ is the surrounding temperature, and $T_{B}$ is the surface temperature on the boundary of the solving area.

\section{Results and Discussion}

5.1. Temperature Field. The correct temperature field is the prerequisite for simulating the grains microstructure during the solidification of the molten pool. Figure 6 shows the temperature distribution on conditions that the laser power is $2000 \mathrm{~W}$ and the scanning time is $3 \mathrm{~s}$. The molten pool is symmetric because of the constant input laser power. It has the larger temperature distribution on the $Z$ direction.

In order to illustrate the temperature distribution in the single point laser cladding, the temperature at different positions on the $Z$ direction is analyzed in the Figures 7 and 8 .

Figure 7 is the temperature curves at different parts in the molten pool during the single point laser cladding. From 0 to 3 second, the base is heated and the powder is melted with the scanning of the laser beam, and then the molten pool is formed. The highest temperature of the molten pool rises to nearly $2150^{\circ} \mathrm{C}$ from $25^{\circ} \mathrm{C}$. Figure 8 is the temperature curves at different positions during the solidification of the molten pool. Temperature at positions 1, 2, and 3 drops after 3.0 second while the temperature at the positions 4 and 5 still rises because the heat at positions 1, 2, and 3 transferring to positions 4 and 5 makes the temperature at positions 4 and 5 increase. At 3.2 second, the temperature drops down to the $1718^{\circ} \mathrm{C}$ which illustrates the molten pool beginning to solidify. The temperature between 3.3 second and 3.6 second is not changed because of the release of the latent heat which makes the energy balance. After 3.6 second, the temperature drops 


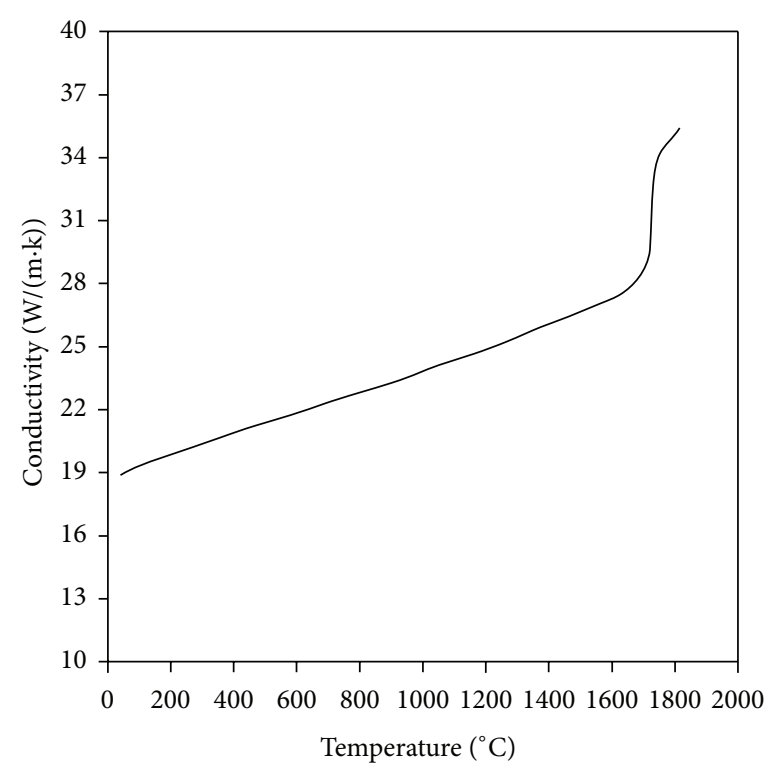

(a)

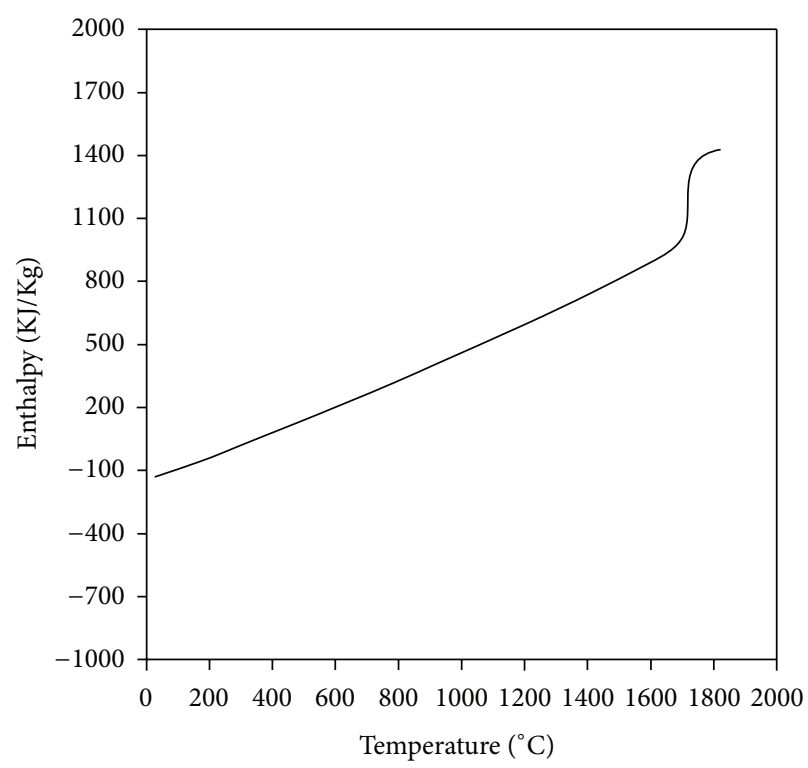

(c)

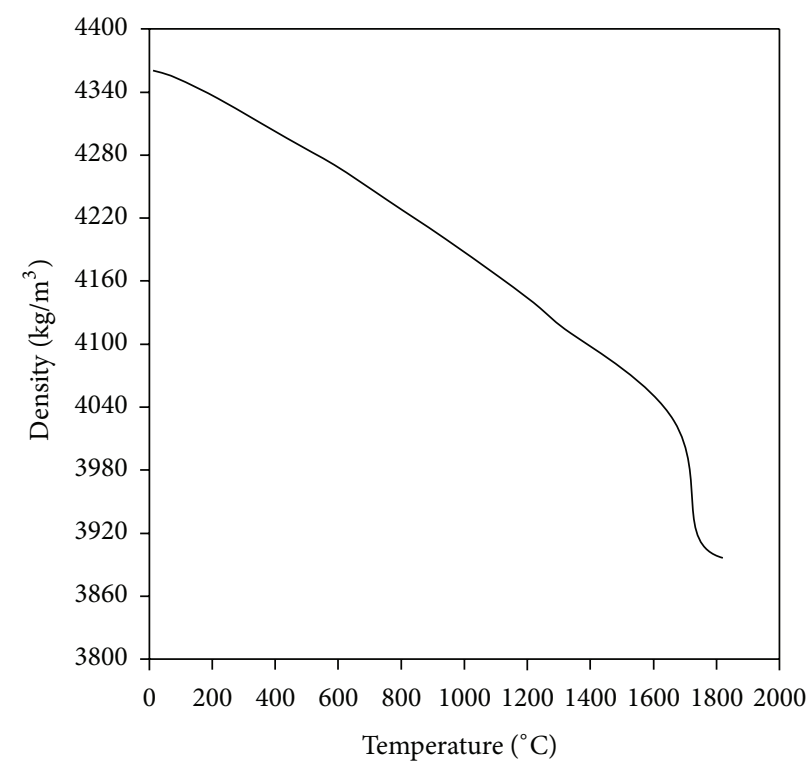

(b)

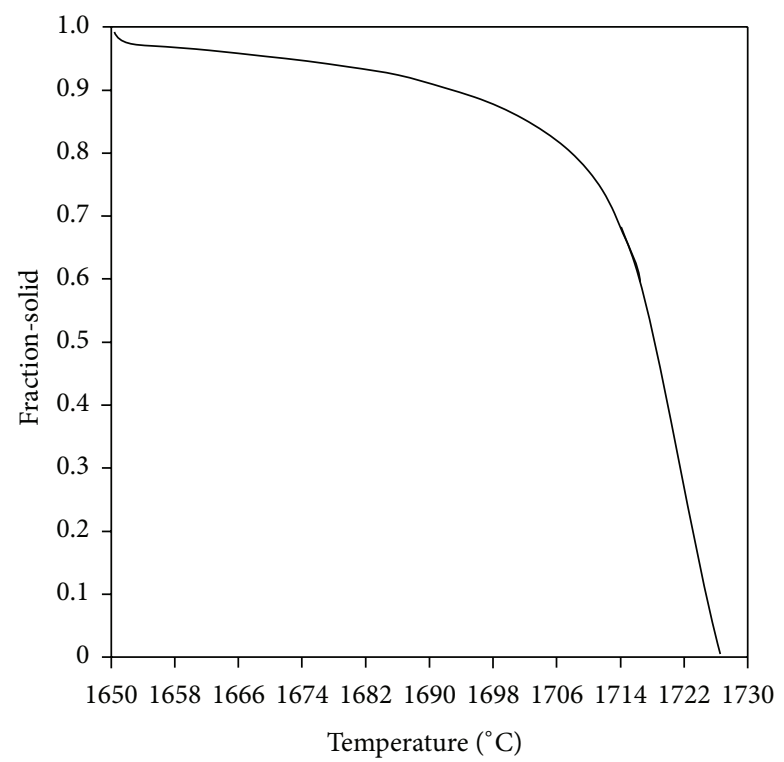

(d)

FIGURE 5: Thermophysical perimeters of TC4 titanium alloy, (a) conductivity, (b) density, (c) enthalpy, and (d) fraction.

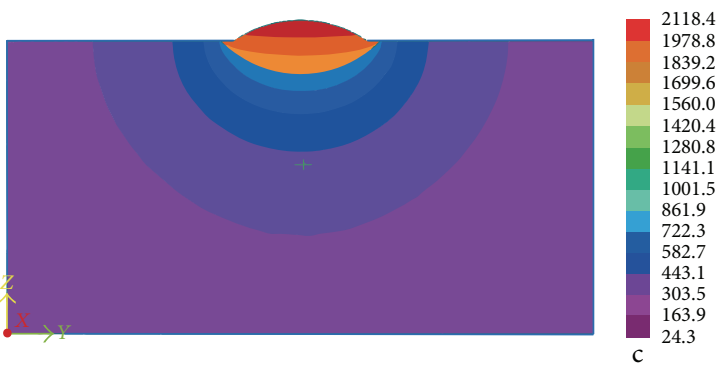

FIgURE 6: Temperature distribution on conditions that the laser power is $2000 \mathrm{~W}$ and the scanning time is $3 \mathrm{~s}$. rapidly. The whole solidification time is about $0.4 \mathrm{~s}$ which confirms the rapid solidification in the laser cladding.

Figures 9 and 10 show the temperature distribution curves on the $Z$ direction with different laser powers and laser scanning time. The maximum temperature in the molten pool increases with the laser power and the scanning rate. The laser power has a larger influence on the temperature distribution of the molten pool than the scanning rate, while the temperature of the heat-affected zone and the base are little affected by the laser power. On condition of the constant scanning time, the range of the maximum temperature is from $1894^{\circ} \mathrm{C}$ to $2445^{\circ} \mathrm{C}$. 


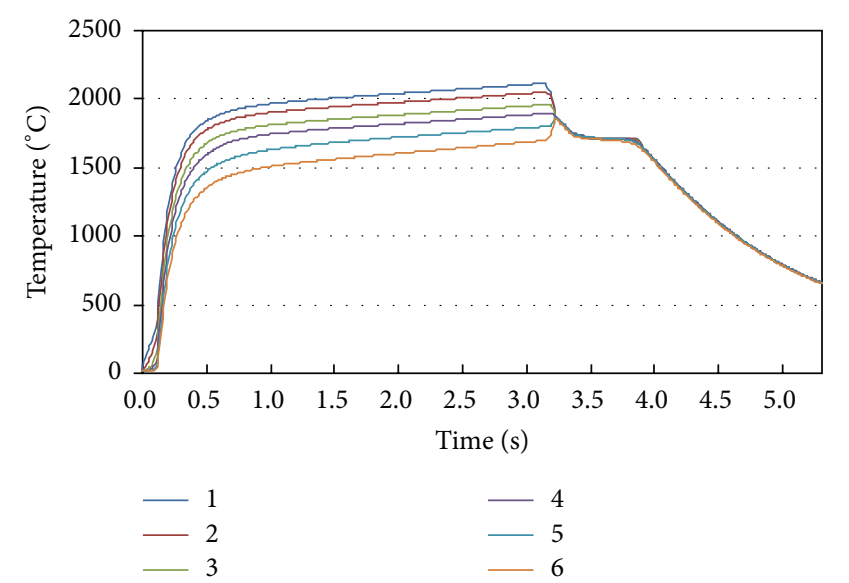

FIgURE 7: Temperature curves at different parts in the molten pool during the single point laser cladding.

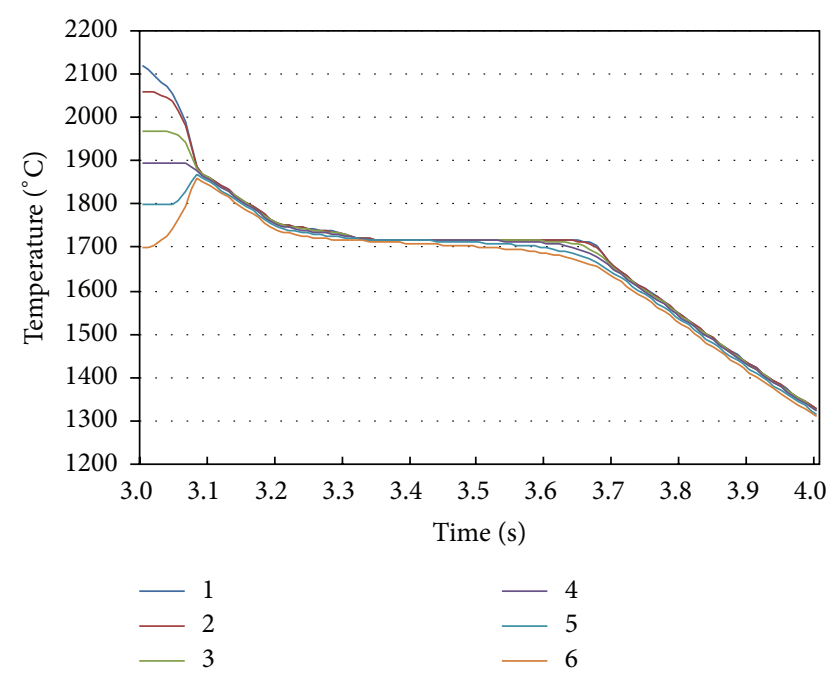

FIGURE 8: Temperature curves at different positions in the molten pool during the solidification.

5.2. Microstructure of the Grains. Based on the CAFE model, the grain microstructure was simulated during the solidification of TC4 titanium alloy in the single point laser cladding. The laser power is $2000 \mathrm{~W}$ and the scanning time is $3 \mathrm{~s}$.

The growth of the grain has a close relationship with the temperature distribution of the molten pool in the single point laser cladding. Figure 11 shows the simulation results of the grain microstructure at $3.3 \mathrm{~s}, 3.4 \mathrm{~s}, 3.5 \mathrm{~s}$, and $3.6 \mathrm{~s}$, respectively. The height of the molten pool is $0.597 \mathrm{~mm}$ and the radius of the molten pool is $1.367 \mathrm{~mm}$. Different colors represent different grains which grow from the bottom of the molten pool. There are four grains in this section. The simulative mean radius of the grains, $0.138 \mathrm{~mm}$, is close to the experimental result, $0.15 \mathrm{~mm}$.

At the beginning of the solidification, the heat at the bottom of the molten pool transfers faster than that at the top of the molten pool because the bottom contacts with the microthermal base while the top of the pool is exposed in

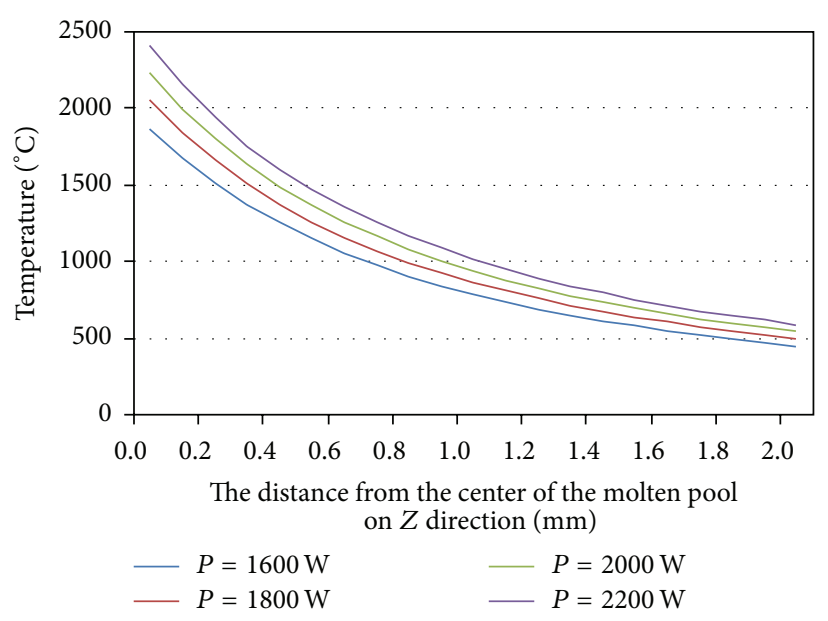

FIGURE 9: Temperature distribution curves on the $Z$ direction with different laser powers.

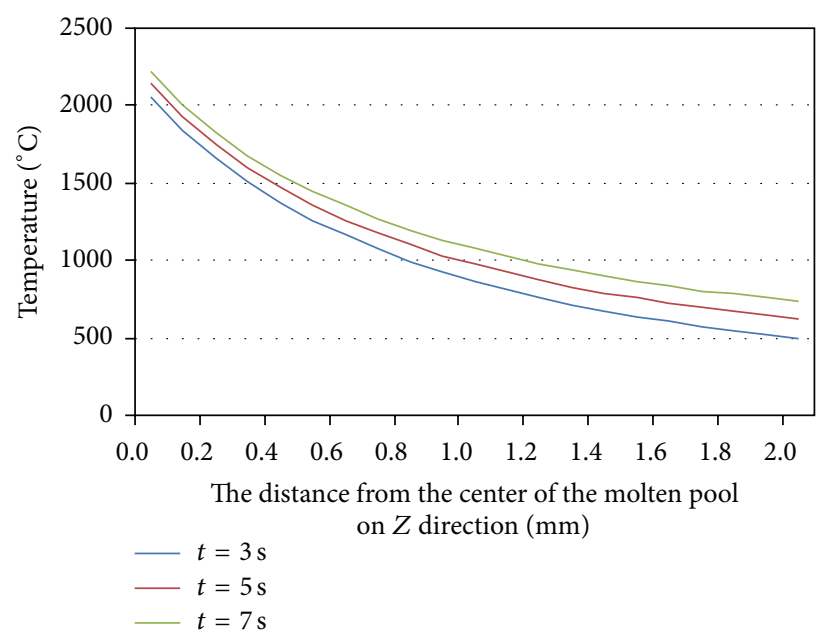

Figure 10: Temperature distribution curves on the $Z$ direction with different laser scanning time.

the surrounding medium. The cells on the wall of the molten pool grow up to the grains which are random orientation in the way of the heterogeneous nucleation. During the process of the grain growth, the faster growing grains are perpendicular to the temperature gradients in the molten pool. The grains on the other directions were inhibited to grow. The maximum temperature gradient in the molten pool is $2500 \times 10^{6 \circ} \mathrm{C} / \mathrm{m}$. So the grains rapidly grow into the molten pool and then the columnar crystals are formed. Figure 12 is the fraction solid of the molten pool during the solidification at $3.0 \mathrm{~s}, 3.1 \mathrm{~s}, 3.3 \mathrm{~s}$, and $3.6 \mathrm{~s}$. It also shows the process of the solidification of the molten pool.

Figure 13(a) is the experimental microstructure of the global molten pool. Compared with Figure 11(d), it can be seen that the simulated results are similar to the experimental results. As the solidification continues, there are only columnar crystals appearing and growing bigger because of 


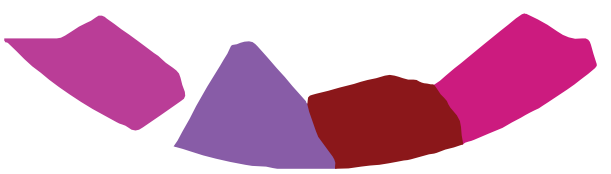

(a) $t=3.3 \mathrm{~s}$

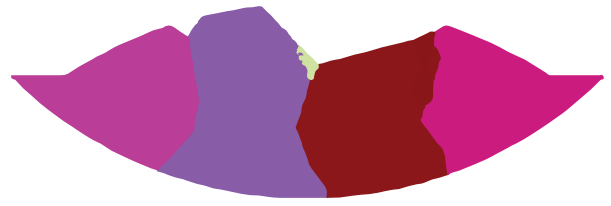

(c) $t=3.5 \mathrm{~s}$

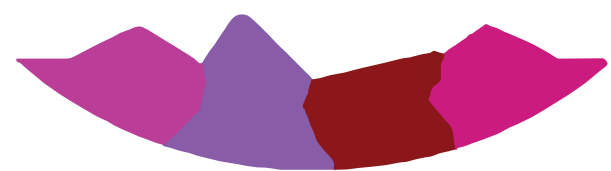

(b) $t=3.4 \mathrm{~s}$

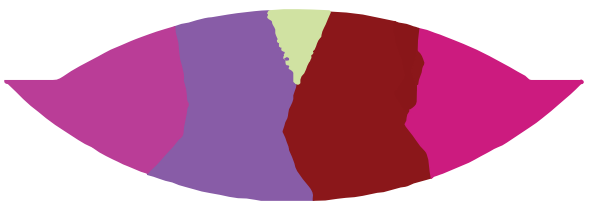

(d) $t=3.6 \mathrm{~s}$

FIGURE 11: Simulation results of the grain microstructure at different times, (a) $3.3 \mathrm{~s}$, (b) $3.4 \mathrm{~s}$, (c) $3.5 \mathrm{~s}$, and (d) $3.6 \mathrm{~s}$.

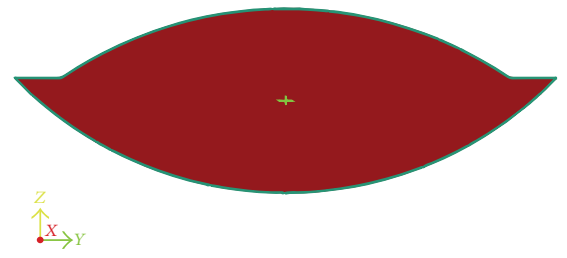

(a) $t=3.0 \mathrm{~s}$

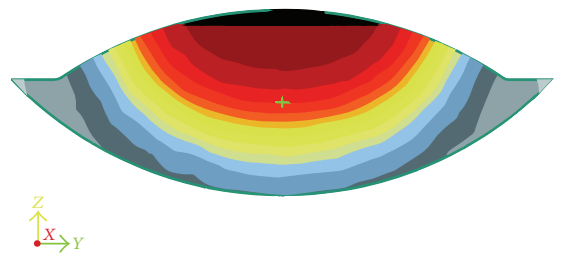

(c) $t=3.3 \mathrm{~s}$

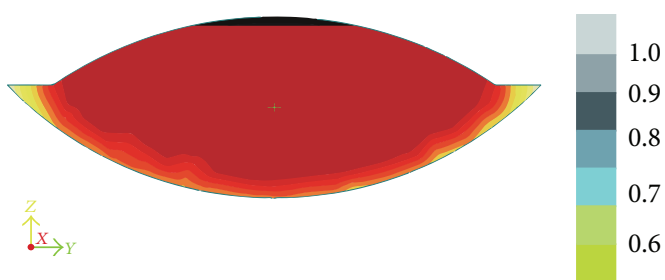

(b) $t=3.1 \mathrm{~s}$

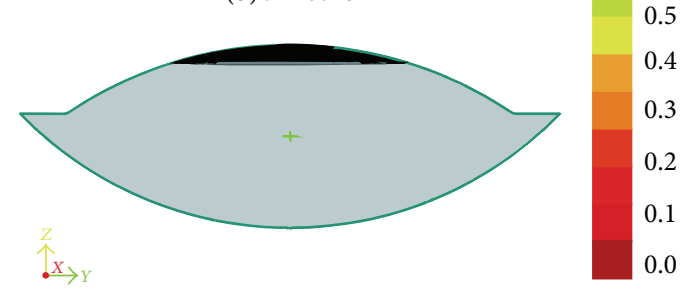

(d) $t=3.6 \mathrm{~s}$

Figure 12: Fraction solid of the molten pool during the solidification at different times, (a) $3.0 \mathrm{~s}$, (b) $3.1 \mathrm{~s}$, (c) $3.3 \mathrm{~s}$, and (d) $3.6 \mathrm{~s}$.

the high cooling rate in the molten pool. Figure $13(\mathrm{~b})$ is the experimental microstructure of the local molten pool.

In the laser cladding forming experiments, the input laser energy varies in different process parameters which have the great influence on the depths of the molten pools. Based on the microstructure experiments; Table 2 shows the depths of the molten pools on different laser process parameters. The depths of the molten pools increase with the laser power and the scanning rate. The range of the depths is from $0.305 \mathrm{~mm}$ to $0.740 \mathrm{~mm}$.

\section{Conclusions}

(1) The paper established the CAFE model to simulate the grain structure during the solidification of Ti-6Al$4 \mathrm{~V}$ alloy in the molten pool of the single point laser cladding. The model solves the heat transfer equation in the molten pool by FE method to calculate the temperature distribution. And then the growth of the grains in the molten pool was simulated based on the temperature field.

(2) The maximum temperature in the molten pool increases with the laser power and the scanning rate.
TABLE 2: Depths of the molten pools on different laser process parameters (unit: $\mathrm{mm}$ ).

\begin{tabular}{lcccc}
\hline \multirow{2}{*}{ Scanning time } & \multicolumn{4}{c}{ Laser power } \\
& $P=1600 \mathrm{~W}$ & $P=1800 \mathrm{~W}$ & $P=2000 \mathrm{~W}$ & $P=2200 \mathrm{~W}$ \\
\hline$t=3 \mathrm{~s}$ & 0.305 & 0.358 & 0.579 & 0.595 \\
$t=5 \mathrm{~s}$ & 0.516 & 0.411 & 0.653 & 0.668 \\
$t=7 \mathrm{~s}$ & 0.589 & 0.600 & 0.726 & 0.740 \\
\hline
\end{tabular}

On condition of the constant scanning time, the range of the maximum temperature is from $1894^{\circ} \mathrm{C}$ to $2445^{\circ} \mathrm{C}$ with the increase of the laser power. In addition, the laser power has a larger influence on the temperature of the molten pool than the scanning rate.

(3) The growth of the grain has a close relationship with the temperature distribution of the molten pool in the single point laser cladding. During the process of the grain growth, the faster growing grains are perpendicular to the temperature gradients in the molten pool. As the solidification continues, the columnar crystals grow bigger and there is little sign 


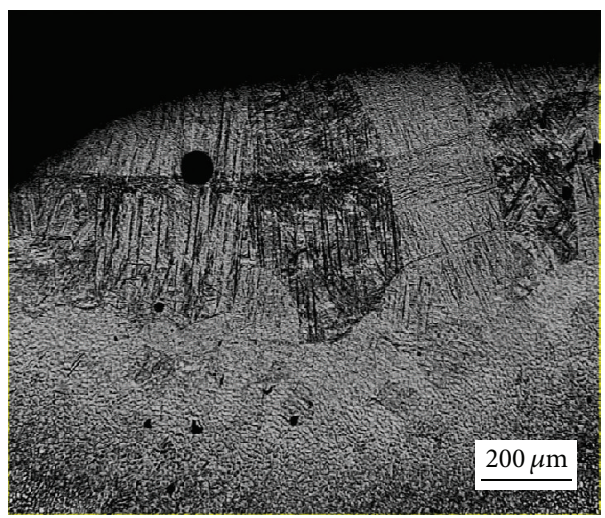

(a)

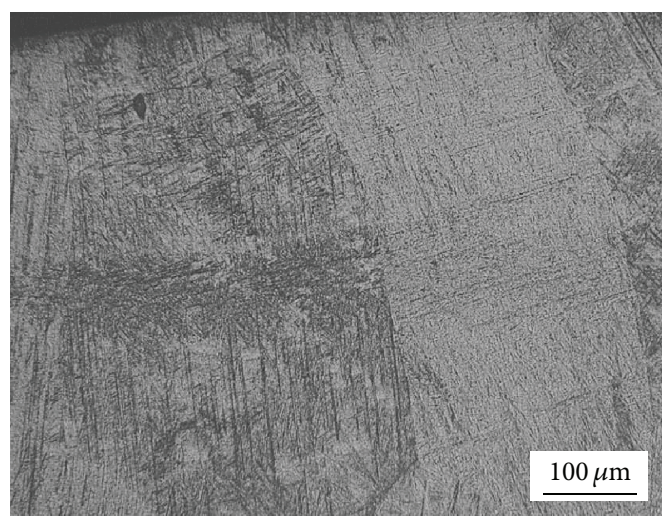

(b)

FIGURE 13: (a) Experimental microstructure of the global molten pool; (b) experimental microstructure of the local molten pool.

of the isometric crystals. The mean radius of the grains in the simulation is $0.138 \mathrm{~mm}$.

(4) This study has very important significance for improving the quality of the structure parts manufactured from the laser cladding forming and the future related research work. The CAFE model is a useful tool for studying the solidification microstructure changing in the laser cladding forming.

\section{Conflict of Interests}

The authors declare that there is no conflict of interests regarding the publication of this paper.

\section{Acknowledgments}

This research is supported by the National Natural Science Foundation of China (no. 51205261). The authors appreciate the Key Laboratory of Fundamental Science for National Defense of Aeronautical Digital Manufacturing Process and Shenyang Aerospace University.

\section{References}

[1] H.-M. Wang, S.-Q. Zhang, and H.-B. Shang, “The developments in laser rapid forming technology research of the large titanium alloy structures," Aviation Precision Manufacturing Technology, vol. 44, no. 6, pp. 28-30, 2008.

[2] J. Mazumder, J. Choi, K. Nagarathnam, J. Koch, and D. Hetzner, "The direct metal deposition of H13 tool steel for 3-D components," JOM, vol. 49, no. 5, pp. 55-60, 1997.

[3] F. Abe, K. Osakada, M. Shiomi, K. Uematsu, and M. Matsumoto, "The manufacturing of hard tools from metallic powders by selective laser melting," Journal of Materials Processing Technology, vol. 111, no. 1-3, pp. 210-213, 2001.

[4] Y. Huang, D. Zou, G. Liang, and J. Su, "Numerical simulation on cladding track, fluid flow field and temperature field in laser cladding process with powder feeding," Rare Metal Materials and Engineering, vol. 32, no. 5, pp. 330-334, 2003.

[5] W. Qi and J. Zhang, "Simulation of the microstructure evolution of aluminum alloy by using cellular automaton-finite element method," Journal of Inner Mongolia University of Science and Technology, vol. 27, no. 1, 2003.

[6] W. Qi, J. Zhang, B. Wang et al., "Three-dimensional simulation of solidified microstructure of $\mathrm{Fe}-\mathrm{C}$ alloy with cellular automaton-finite element method," The Chinese Journal of Process Engineering, vol. 8, no. 1, pp. 64-67, 2008.

[7] S. Bo-wei, W. Lei, L. Xin, and W. Wei-dong, "Progresses in numerical simulation of solidification microstructure using cellular automaton method," Foundry, vol. 55, no. 5, pp. 439443, 2006.

[8] B.-C. Liu and T. Xing, Simulation and Quality Control in Casting Engineering, China Machine Press, 2001.

[9] Y. Yu and G. Yang, "Research development of microstructure numerical simulation in the solidification," vol. 3, pp. 30-33, 2002.

[10] X. F. Shang, Z. J. Wang, D. X. Han, and Z. T. Xie, "Research on defects of titanium alloy laser rapid forming," Advanced Materials Research, vol. 189-193, pp. 3726-3730, 2011.

[11] X. Lin, H.-O. Yang, J. Chen, and W.-D. Huang, "Microstructure evolution of 316L stainless steel during laser rapid forming," Acta Metallurgica Sinica, vol. 42, no. 4, pp. 361-368, 2006.

[12] X. Zhan, Z. Dong, Y. Wei, and Y. Wang, "Simulation of columnar dendrite grain growth in weld pool of Ni-Cr binary alloy," The Chinese Journal of Nonferrous Metals, vol. 19, no. 8, pp. 14311436, 2009.

[13] S.-M. Seo, I. Kim, C. Jo, and K. Ogi, "Grain structure prediction of Ni-base superalloy castings using the cellular automatonfinite element method," Materials Science and Engineering A, vol. 448-451, pp. 713-716, 2007.

[14] H. Yin and S. D. Felicelli, "Dendrite growth simulation during solidification in the LENS process," Acta Materialia, vol. 58, no. 4, pp. 1455-1465, 2010.

[15] L. Peng, S. Hai-Bo, L. Yang, and Z. Jia-Quan, "3D CAFE model for simulating thesolidification microstructure of 430 stainless steel," Journal of University of Science and Technology Beijing, vol. 36, no. 3, pp. 315-322, 2014.

[16] M. Rappaz and Ch.-A. Gandin, "Probabilistic modelling of microstructure formation in solidification processes," Acta Metallurgica et Materialia, vol. 41, no. 2, pp. 345-360, 1993.

[17] Ch.-A. Gandin and M. Rappaz, "A coupled finite elementcellular automaton model for the prediction of dendritic grain structures in solidification processes," Acta Metallurgica et Materialia, vol. 42, no. 7, pp. 2233-2246, 1994. 
[18] W. Kurz, B. Giovanola, and R. Trivedi, "Theory of microstructural development during rapid solidification," Acta Metallurgica, vol. 34, no. 5, pp. 823-830, 1986.

[19] W. Jin-long, L. Chao-bin, W. Fu-ming, J. Zhang, and W. Ren, "Mechanism and application of CAFE method," Journal of Iron and Steel Research, vol. 21, no. 10, pp. 60-63, 2009.

[20] G. Chen, X. Li, D. Zuo, and H. Wang, "Solidification analysis during laser cladding process based on finite element," China Mechanical Engineering, vol. 23, no. 4, pp. 468-473, 2012. 


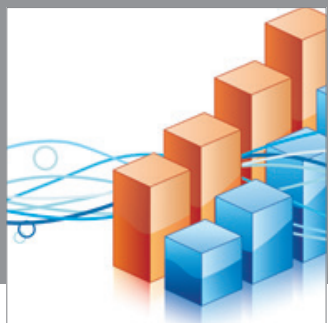

Advances in

Operations Research

mansans

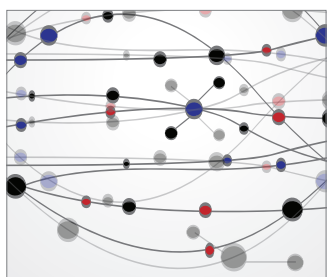

The Scientific World Journal
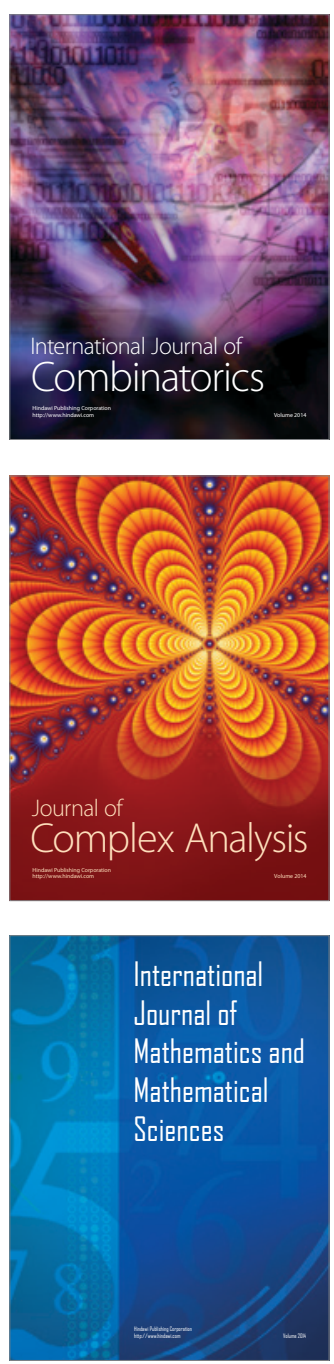
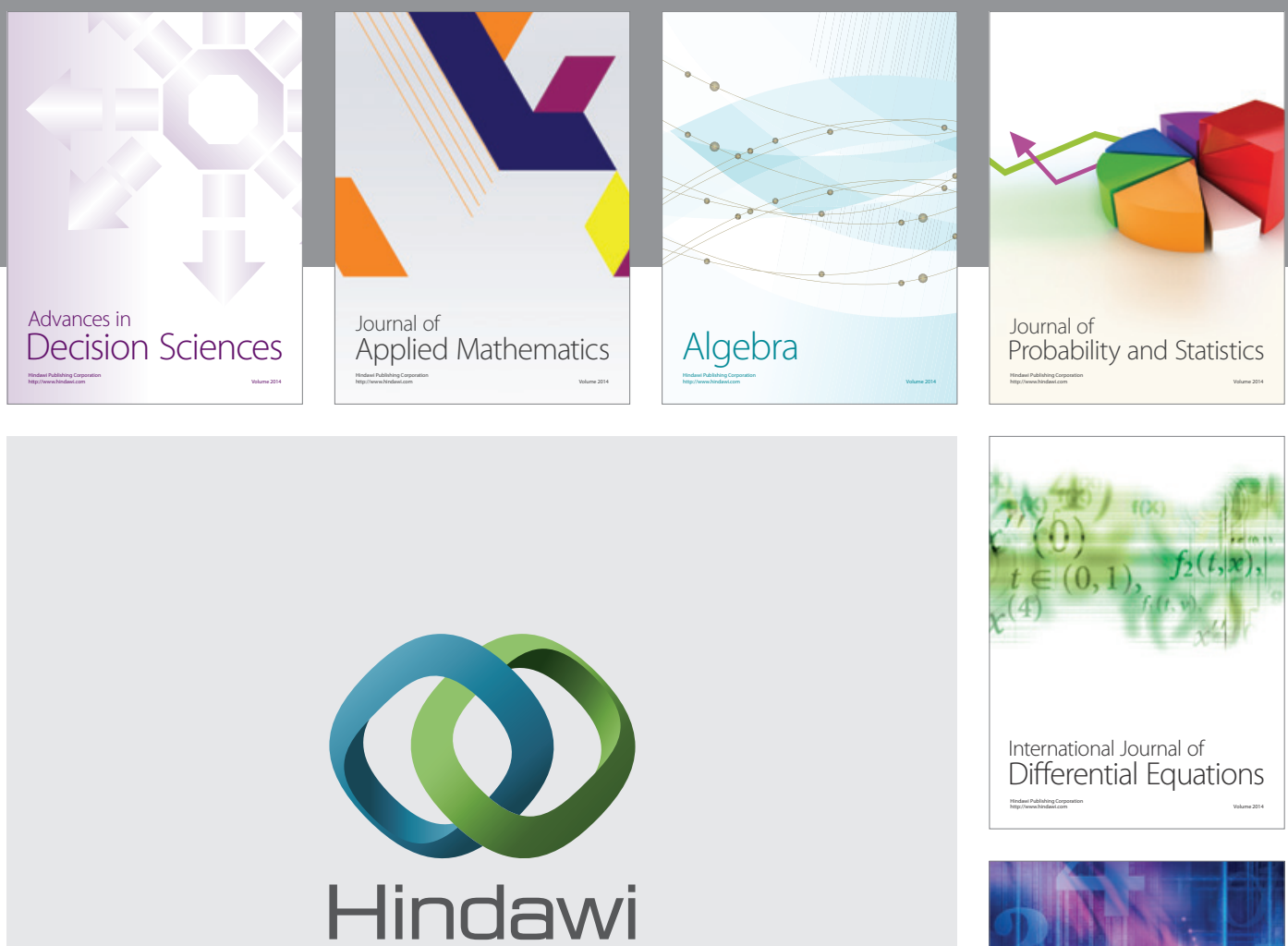

Submit your manuscripts at http://www.hindawi.com
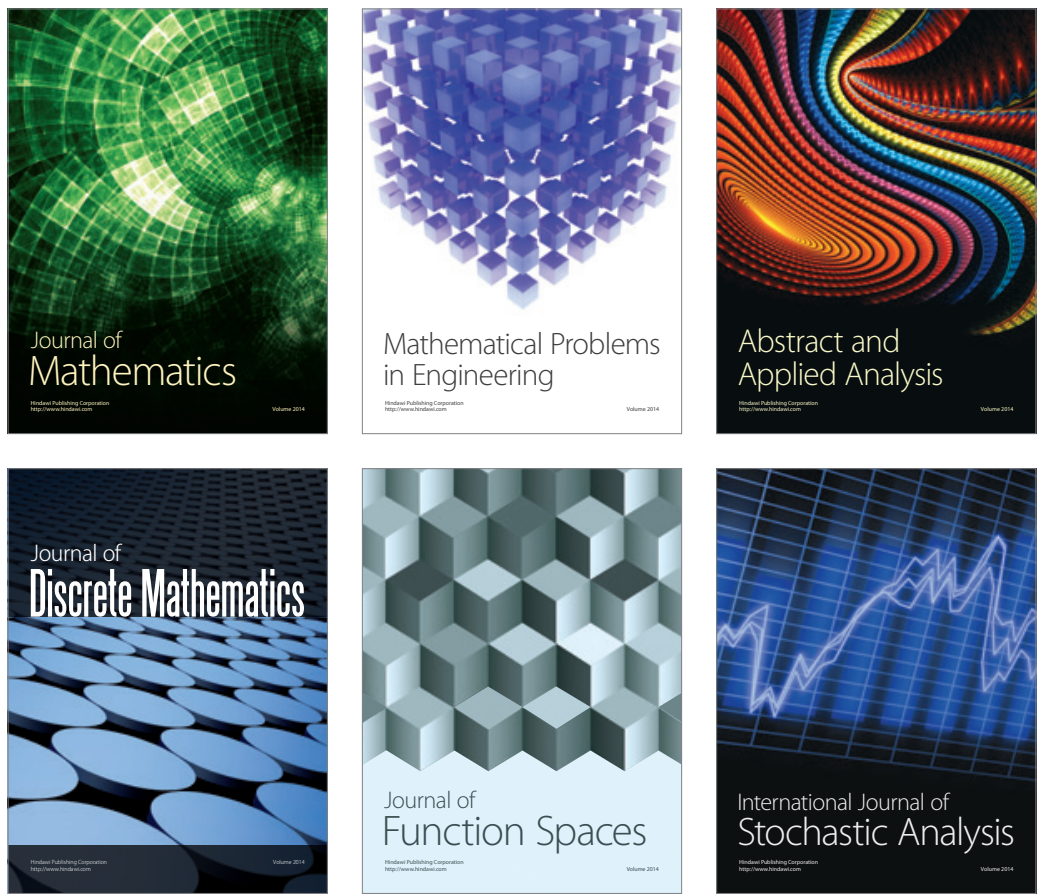

Journal of

Function Spaces

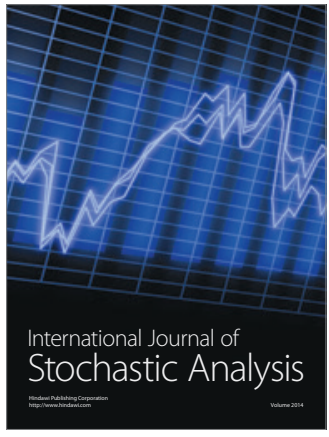

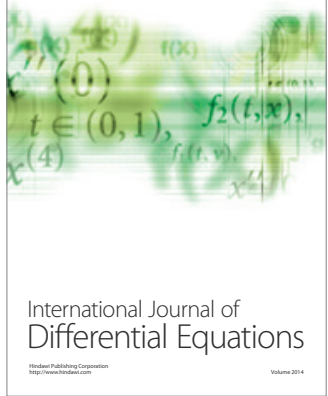
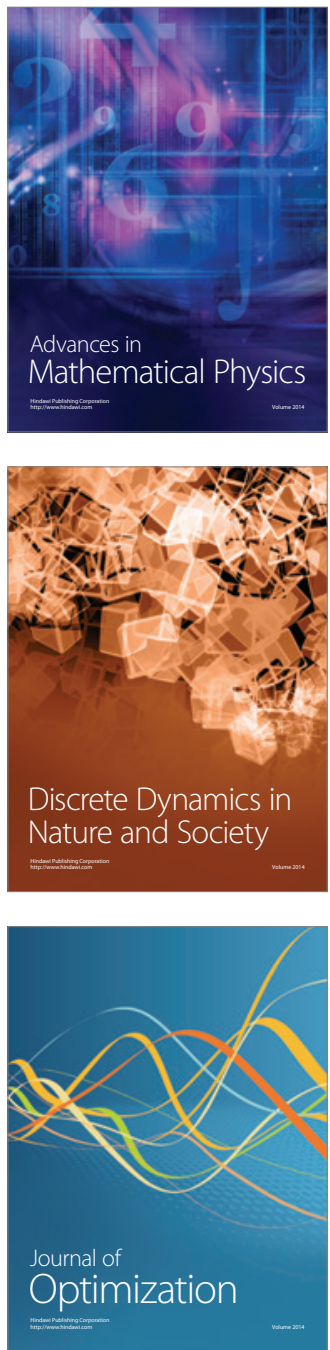